\title{
Epidermoid Septal Carcinoma, A Rare and Singular Tumor: Case Report and Review
}

\author{
Tomàs Pérez-Carbonell ${ }^{1}$, Felipe Ferrer-Baixauli ${ }^{2}$, Ignacio Pla-Gil ${ }^{3}$, Pedro Segarra-Cortés ${ }^{4}$, Jaime Marco-Algarra ${ }^{5}$
}

\begin{abstract}
Aim: To describe our casuistic and the way we manage these tumors with their differential behavior.

Background: Septal epidermoid carcinoma is a rare tumor that accounts for only $9 \%$ of tumors of the nasal fossa. This tumor presents histological, clinical, and prognostic characteristics that differentiate it from other nasal cavity tumors, mainly its anterior location that leads to an early diagnosis in incipient stages.

Case description: We present a series of six patients diagnosed with nasal squamous cell carcinoma as well as the clinic referred by the patients to the diagnosis, the associated risk factors, and their clinical and therapeutic approach.

Conclusion: The majority of cases (4/6) corresponded to early stages I and II, while the rest were classified as stage IV. In all cases, surgical treatment was performed using different approaches according to location and stage and completing treatment with radiotherapy in five of the six patients. After an average of $\mathbf{4 0}$ months of follow-up, all the patients were free of disease.

Clinical significance: This paper tries to explain many points of controversy in the management of the tumors of the most anterior areas of the nasal fossa and its differential characteristics with respect to the rest of the tumors in this area.

Keywords: Nasal cavity, Nasal septum, Nose neoplasms, Squamous cell carcinoma.

Clinical Rhinology An International Journal (2019): 10.5005/jp-journals-10013-1352
\end{abstract}

\section{BACKGROUND}

The nasal cavity and paranasal sinuses are infrequent sites of primary tumors or metastasis. ${ }^{1}$ Indeed, nasosinusal tumors represent only $5 \%$ of head and neck tumors and only $1 \%$ of the malignant neoplasias throughout the body. ${ }^{2}$ Due to the specific anatomical and histological peculiarities of this site, nasosinusal tumors are divided into tumors of the paranasal sinuses and tumors of the nasal cavity. The latter can be further grouped into different types: septal tumors, those in the floor of the nasal cavity, tumors of the vestibule, and those of the lateral wall. The nasal cavity tumors represent $0.5 \%$ of all the neoplasias in the human body, $3 \%$ of the head and neck tumors, and $30 \%$ of the nasosinusal tumors, ${ }^{3}$ whereas tumors localized to the septum represent only $9 \%$ of the nasal cavity tumors. It has been found that the most prevalent histology among nasal cavity tumors is that of an epidermoid carcinoma ${ }^{4}$ detected in approximately $50 \%$ of cases. ${ }^{5}$

Given the more anterior localization with respect to other endonasal structures, septal tumors have a more characteristic behavior that favors its diagnosis during the initial stages of its formation. They are usually evident as a fungating or ulcerated lesion in the nasal cavity. Nevertheless, as it is associated with a nonspecific rhinological state in clinical terms, such as rhinorrhoea or epistaxis, its diagnosis would be delayed until the lesion becomes visible. ${ }^{6}$ In terms of its histology, these septal tumors can also be differentiated from the rest of the nasal cavity tumors, as they almost exclusively adopt an epidermoid carcinoma histology ${ }^{7}$ except for a few cases. ${ }^{8}$ These features are associated with the better prognosis and therapeutic response of this tumor.

\section{Case Description}

We conducted a retrospective review of the cases diagnosed with nasal cavity tumor with a septal sublocalization, who attended our center during a period of 5 (2012-2017).
${ }^{1-5}$ Department of ENT, University Hospital of Valencia, University of Valencia, Valencia, Spain

Corresponding Author: Tomàs Pérez-Carbonell, Department of ENT, University Hospital of Valencia, University of Valencia, Valencia, Spain, Phone: +34 637228468, e-mail: tperezcarbonell@gmail.com

How to cite this article: Pérez-Carbonell T, Ferrer-Baixauli F, Pla-Gil I, et al. Epidermoid Septal Carcinoma, A Rare and Singular Tumor: Case Report and Review. Clin Rhinol An Int J 2019;12(1):27-30.

Source of support: Nil

Conflict of interest: None

We considered that the tumor originated in the nasal septum region when its root was actually established in the septum, although the more advanced tumors reached other areas of the nasal cavity. In those cases, we considered that the tumor was septal if the majority of its roots were in the septum.

All patients were staged following the last update of the tumor-node-metastasis (TNM) classification. Initially, a radiological study was carried out using computerized tomography (CT), and an endoscopic exploration was performed taking a biopsy of the lesion.

Once the patients were diagnosed, they underwent different therapeutic protocols following the regimens proposed by the clinical guide for the management, diagnosis, and treatment of tumors of the head and neck of the NCCN (National Comprehensive Cancer Network). ${ }^{9,10}$

Between 2012 and 2017, six cases of epidermoid carcinoma of the nasal septum were studied at our center. The distribution by sex was of 5 men and 1 woman, and the average age of the patients at the time of diagnosis was 71 years old (range 61-86). The risk factors are reported in Table 1. We must point out the prior

() The Author(s). 2019 Open Access This article is distributed under the terms of the Creative Commons Attribution 4.0 International License (https://creativecommons. org/licenses/by-nc/4.0/), which permits unrestricted use, distribution, and non-commercial reproduction in any medium, provided you give appropriate credit to the original author(s) and the source, provide a link to the Creative Commons license, and indicate if changes were made. The Creative Commons Public Domain Dedication waiver (http://creativecommons.org/publicdomain/zero/1.0/) applies to the data made available in this article, unless otherwise stated. 
Table 1: Structured summary of each case. OS: open surgery using lateronasal rhinotomy. ES: Endoscopic surgical approach. RT: adjuvant radiotherapy treatment

\begin{tabular}{|c|c|c|c|c|c|c|c|c|}
\hline Patient & Age & Risk factors & $\begin{array}{l}\text { Time since } \\
\text { syntoms }\end{array}$ & Affected structures & TNM & Stage & Treatment & Disease time free \\
\hline 1 & 61 & Tobbaco & $1,5 \mathrm{~m}$ & $1 / 3$ anterior septum & T1N0M0 & I & ES & $\begin{array}{l}\text { Disease free after } 22 \\
\text { months }\end{array}$ \\
\hline 2 & 81 & $\begin{array}{l}\text { Previous } \\
\text { neoplasia, } \\
\text { Tobbaco }\end{array}$ & $3 \mathrm{~m}$ & $\begin{array}{l}1 / 3 \text { anterior septum }+ \\
\text { medial crus involvement }\end{array}$ & T2NOMO & II & OS & $\begin{array}{l}\text { Recurrence at } 12 \text { months- } \\
>\mathrm{OS}+\mathrm{RT}->\text { Disease free } \\
\text { after } 70 \text { months }\end{array}$ \\
\hline 3 & 63 & $\begin{array}{l}\text { Tobbaco, } \\
\text { Alcohol }\end{array}$ & $6 \mathrm{~m}$ & $\begin{array}{l}1 / 3 \text { anterior septum }+ \\
\text { Narina \& NF vestibule }\end{array}$ & T2NOMO & II & $\mathrm{OS}+\mathrm{RT}$ & $\begin{array}{l}\text { Disease free } 24 \text { months. } \\
\text { EXITUS }\end{array}$ \\
\hline 4 & 86 & Tobbaco & $3 m$ & $\begin{array}{l}1 / 3 \text { anterior septum }+ \\
\text { NF vestibule }\end{array}$ & T2NOMO & II & $\mathrm{OS}+\mathrm{RT}$ & $\begin{array}{l}\text { Recurrence at } 7 \text { months-> } \\
\text { OS+ RT-> Disease free } 50 \\
\text { months. }\end{array}$ \\
\hline 5 & 70 & Tobbaco & $3 \mathrm{~m}$ & $1 / 3$ anterior + Skin & T4aNOMO & IVa & $\mathrm{OS}+\mathrm{RT}$ & $\begin{array}{l}\text { Disease free after } 38 \\
\text { months }\end{array}$ \\
\hline 6 & 66 & $\begin{array}{l}\text { Tobbaco, } \\
\text { Alcohol }\end{array}$ & $1,5 \mathrm{~m}$ & $\begin{array}{l}\text { 2/3 posterior septum+ } \\
\text { ethmoid, ipsilateral } \\
\text { lamina papyracea } \\
\text { and sphenoid sinus } \\
\text { involvement }\end{array}$ & T4aNOMO & IVa & $\mathrm{ES}+\mathrm{RT}$ & $\begin{array}{l}\text { Disease free after } 36 \\
\text { months }\end{array}$ \\
\hline
\end{tabular}

oncological history in three patients in complete remission at the time of diagnosis (two patients had a primary lung tumor and one patient had a cutaneous epidermoid carcinoma) (Table 1).

Regarding the symptomatology, the majority of the patients $(5 / 6)$ went to see a doctor due to the presence of a mass or ulceration in the anterior nasal area. Less frequently, they referred to other accompanying symptoms, such as obstruction (1/6), rhinorrhea $(2 / 6)$, anosmia (2/6), or epistaxis (2/6). All patients reported more than one symptom at the time of diagnosis, and they indicated delayed referral to an ENT specialist by 3 months from the onset of the symptomatology.

Only one of the patients was classified as stage I (T1NOMO), since the tumor location was limited to the anterior one-third of the nasal septum, with no involvement of contiguous areas. Most of the cases (3/6) were classified as stage II (T2NOM0), since the tumor lesion reached a contiguous region. Notably, in all these cases, the lesions were located in the anterior septum with columellar involvement (Fig. 1). As for the rest of the cases (2/6), they were staged as stage IVa (T4aNOM0). One of these was a larger lesion with a more posterior location, affecting the posterior two-thirds of the septum, ipsilateral ethmoid, lamina papyracea, and sphenoidal sinus (Fig. 2). The other case was a small tumor with an anterior location, yet it had infiltrated into the skin.

In the radiological studies, none of the cases presented adenopathies suggestive of malignancy, and therefore they were all staged as N0. The anatomopathological results of the biopsies taken from the lesions were all classified as epidermoid carcinoma. In patients with stage II lesions, due to their anterior location and the columellar involvement, a combined approach was used: endoscopy and an open procedure, performing a lateral rhinotomy to achieve broad exeresis of the tumor. In order to ensure tumorfree margins were obtained, in all cases a complete exeresis of the columella was carried out due to its affectation or infiltration of adjacent structures. An endoscopic approach to treat the lesions was used both on the patient with the earliest stage tumor (stage I) and in the most advanced stage tumor (IVa).

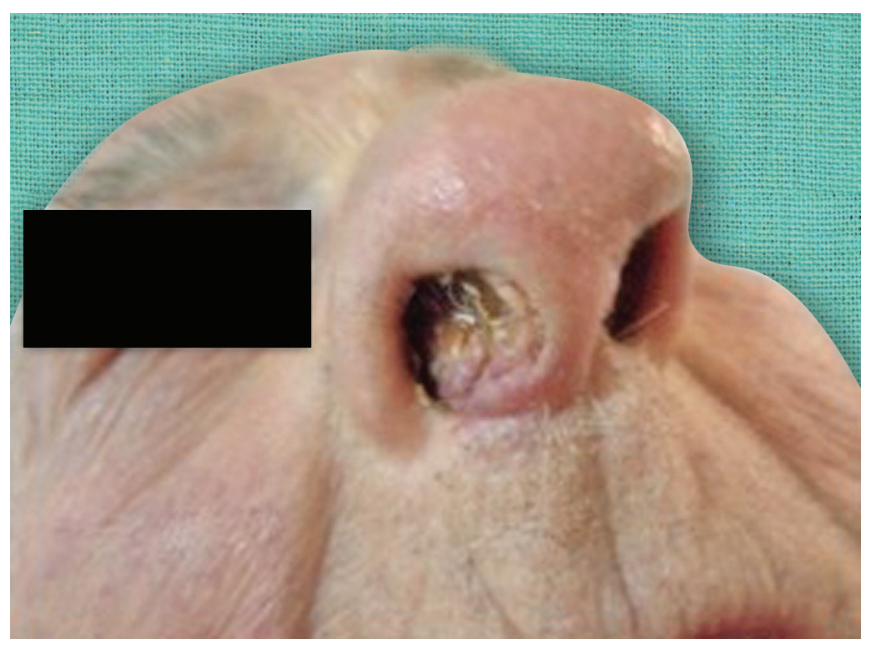

Fig. 1: Patient with septal tumor with columellar involvement, stage II (T2NOMO)

Except for the patient with the earliest stage tumor, the other patients were candidates for adjuvant treatment with radiotherapy. However, only three of them completed the full treatment with surgery plus radiotherapy, as one of them had undergone previous treatment with radiotherapy for cutaneous epidermoid carcinoma and thus could not complete the full radiotherapy protocol. In the other case, the full treatment with radiotherapy could not be administered because of the occurrence of an adverse cutaneous reaction. Two of the patients who presented with a stage II tumor had a local recurrence after 7 and 12 months, respectively, which was successfully treated with a new surgical resection and radiotherapy. One of the patients died 24 months after treatment from causes not related to the tumor. The other five patients were disease free for more than 24 months after the surgical intervention. 

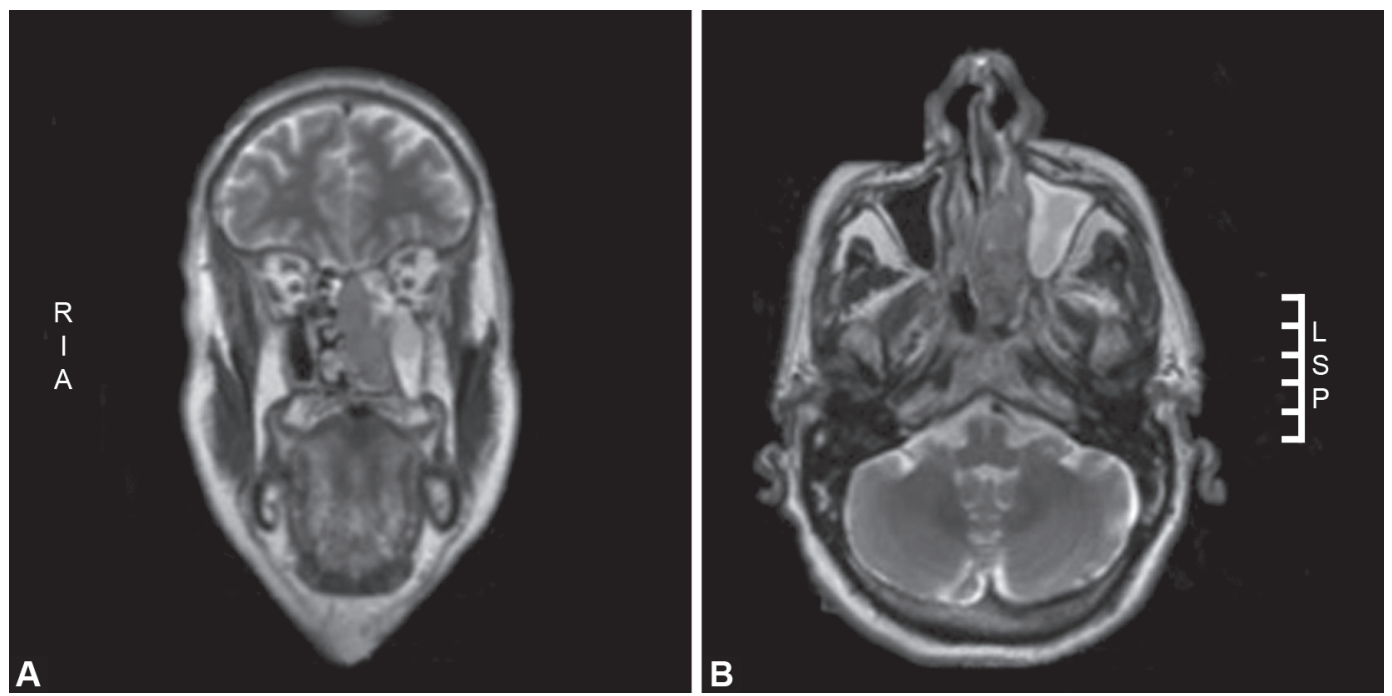

Figs $2 \mathrm{~A}$ and B: Magnetic resonance in T2 series: (A) Coronal section of the tumor of the posterior part of septum in which there is evidence of ethmoid, ipsilateral lamina papyracea and sphenoid sinus involvement; (B) Axial section of tumor involving two-third posterior septum, where extension to the sphenoid sinus and occupation of the ipsilateral maxillary sinus can be lengthened

\section{Discussion}

Epidermoid carcinomas account for $50 \%$ of the tumors in the nasal cavity. Unlike the rest of the tumors, there is evidence that practically all septal tumors are septal epidermoid carcinomas according to Ang. ${ }^{7}$ It is not only their histological nature that differentiates this septal subvariety from the rest of nasal cavity tumors but also its more visible and accessible location. As such, nasal septum tumors are usually diagnosed earlier, and its prognosis is usually better than for other tumors at other endonasal locations.

The low frequency, not only of septal tumors but also of sinonasal tumors in general, has favored the study of these tumors altogether without differentiating based on their location. Since 2001, the AJCC classifies sinonasal tumors into tumors of the paranasal sinuses, ethmoid sinus, and the nasal cavity \{Scurry:2007hy\}. This grouping of tumors based on their location allows a larger number of cases to be dealt with in different series, thereby obtaining better statistical and epidemiological data but disregarding any characteristics specific to each sublocation as the septal sublocation. Indeed, such heterogeneous groupings have generated some controversy over the years, with some authors advocating the need to stage tumors according to their location, arguing that the majority of tumors of the nasal cavity (69\%) correspond to the septal location. ${ }^{11}$

Although the TNM protocol is the staging system most often used at present, a general consensus is yet to be reached as to how to stage these nasosinusal tumors. Some groups even choose to use their own staging system. ${ }^{12-14}$ One of our cases, a small anterior tumor, was considered to be a stage IV tumor (T4aNOM0) because of the involvement of the skin. In our opinion, skin affectation in these small, anterior tumors does not imply that they have the same prognostic severity as other tumors located more posteriorly with skin infiltration. Thus, we believe that the TNM classification should consider these facts in order not to overestimate or overstage these types of tumors.

In our series of patients, the best option for all early stage tumors was surgical treatment associated with concomitant radiotherapy or not. The low incidence of the disease means there are few studies available to obtain clear evidence regarding the best treatment option for these tumors. While surgical treatment associated with postoperative radiotherapy was mainly used previously to most tumors in the anterior part of the nasal cavity, ${ }^{11}$ elsewhere different regimens of radiotherapy alone has been used for stage I and II tumors. ${ }^{14}$ Nevertheless, an analysis of nasosinusal tumors in 4,994 patients led to the conclusion that in patients with localized disease, as in all our cases, there were no significant statistical differences in the 5-year survival of the different therapeutic modalities, with these being $85.71 \%$ for surgery, $80.38 \%$ for surgery plus radiotherapy, and $78.47 \%$ for radiotherapy alone. ${ }^{15}$

One of our most advanced cases, considered as stage IV, was the most controversial regarding its behavior and therapeutic options. This stage IV tumor was diagnosed later, probably due to its more posterior location, and it was therefore at a more advanced stage compared to the others. Due to its large ethmoidal component, this tumor might not have been classified as having a septal location, yet as the septal implantation predominates we consider it a tumor of septal sublocation based on our classification criteria. Another controversial aspect of this case was whether to treat the neck with surgery or with radiotherapy. There is not enough evidence available to recommend cervical treatment in high-grade nasosinusal tumors with no cervical involvement (N0). However, different risks have been reported for the occurrence of cervical metastasis in nasal cavity tumors (excluding those from the paranasal sinuses), which occurs in $5 \%$ to $41 \%$ of all these tumors, although these studies were heterogeneous and with a sample size insufficient to draw any conclusions. A systematic review and a meta-analysis of 23 studies addressing this issue estimated that the relative risk of occurrence of cervical metastasis in tumors at advanced stages of the nasal cavity could be close to $20 \%$.These authors concluded that the relative risk for distant metastases in tumors of the nasal cavity is $18.1 \%$, and therefore, they advocate for prophylactic treatment of the cervical lymph nodes with radiotherapy or selective neck dissection, and they recommend performing a complete cervical dissection in "high-risk" tumors such as those with perineural invasion or lymphovascular invasion, those at advanced stages, and/or large tumors. ${ }^{3}$ 


\section{Conclusion}

Septal epidermoid carcinomas, as well as other tumors of the anterior part of the nasal cavity, behave characteristically in terms of their diagnosis and prognosis. Due to their low incidence, there are few studies that provide sufficient evidence of these features. These tumors are classified into large groups, disregarding some of the distinctive clinical characteristics that distinguish them from other tumor types.

Our experience with this type of tumor favors adopting a surgical approach (except in tumors classified as T4b), followed by radiotherapy, except in those localized cases such as stage T1-2 tumors, where surgical treatment with wide resection margins achieves sufficiently good locoregional control of the disease.

\section{Clinical Significance}

This paper tries to explain the many points of controversy in the management of the tumors of the most anterior areas of the nasal fossa and its differential characteristics with respect to the rest of the tumors of this area.

\section{References}

1. Imai T, Satoh I, Matsumoto K, et al. Clear cell carcinoma of the nasal cavity: a case report from histopathological viewpoint. Auris Nasus Larynx 2016;43(1):108-111. DOI: 10.1016/j.anl.2015.06.002.

2. Hoppe BS, Stegman LD, Zelefsky MJ, et al. Treatment of nasal cavity and paranasal sinus cancer with modern radiotherapy techniques in the postoperative setting — the MSKCC experience. Int J Radiat Oncol Biol Phys 2007;67(3):691-702. DOI: 10.1016/j.jijrobp.2006.09.023.

3. Scurry WC, Goldenberg D, Chee MY, et al. Regional recurrence of squamous cell carcinoma of the nasal cavity: a systematic review and meta-analysis. Arch Otolaryngol Head Neck Surg 2007;133(8): 796-800. DOI: 10.1001/archotol.133.8.796.
4. Weber AL, Stanton AC. Malignant tumors of the paranasal sinuses: radiologic, clinical, and histopathologic evaluation of 200 cases. Head Neck 1984;6(3):761-776. DOI: 10.1002/hed.2890060310.

5. Bhattacharyya N. Cancer of the nasal cavity: survival and factors influencing prognosis. Arch Otolaryngol Head Neck Surg 2002;128(9):1079-1083. DOI: 10.1001/archotol.128.9.1079.

6. DiLeo MD, Miller RH, Rice JC, et al. Nasal septal squamous cell carcinoma: a chart review and meta-analysis. Laryngoscope 1996;106(10):1218-1222. DOI: 10.1097/00005537-199610000-00008.

7. Ang KK, Jiang G-L, Frankenthaler RA, et al. Carcinomas of the nasal cavity. Radiother Oncol 1992;24(3):163-168. DOI: 10.1016/01678140(92)90375-5.

8. Kainuma K, Netsu K, Asamura K, et al. Chondrosarcoma of the nasal septum: a case report. Auris Nasus Larynx 2009;36(5):601-605. DOI: 10.1016/j.anl.2008.12.006.

9. Pfister DG, Ang K, Brockstein B, et al. NCCN practice guidelines for head and neck cancers. Oncology (Williston Park, NY) 2000;14(11A):163-194.

10. López F, Grau JJ, Medina JA, et al. Spanish consensus for the management of sinonasal tumors. Acta Otorrinolaringol Esp 2017;68(4):226-234. DOI: 10.1016/j.otorri.2016.07.001.

11. Fornelli RA, Fedok FG, Wilson EP, et al. Squamous cell carcinoma of the anterior nasal cavity: a dual institution review. Otolaryngol Head Neck Surg 2000;123(3):207-210. DOI: 10.1067/mhn.2000.107450.

12. Wray J, Morris CG, Kirwan JM, et al. Radiation therapy for nasal vestibule squamous cell carcinoma: a 40-year experience. Eur Arch Otorhinolaryngol 2016;273(3):661-669. DOI: 10.1007/s00405-0153603-z.

13. Wang CC. Treatment of carcinoma of the nasal vestibule by irradiation. Cancer 1976;38(1):100-106. DOI: 10.1002/1097-0142(197607)38:1<100::AID-CNCR2820380118> 3.0.CO;2-9.

14. Allen MW, Schwartz DL, Rana $\mathrm{V}$, et al. Long-term radiotherapy outcomes for nasal cavity and septal cancers. Int J Radiat Oncol Biol Phys 2008;71(2):401-406. DOI: 10.1016/j.jijobp.2007.10.031.

15. Sanghvi S, Khan MN, Patel NR, et al. Epidemiology of sinonasal squamous cell carcinoma: a comprehensive analysis of 4994 patients. Laryngoscope 2014;124(1):76-83. DOI: 10.1002/lary.24264. 